\title{
LA RESPUESTA DE JOVELLANOS A MORATÍN COMO RENOVACIÓN DEL DISCURSO POETTCO EPISTOLAR
}

\author{
Elena de LORENZO ÁLVAREZ
}

I.a «Epístola a don Caspar de Jovellanos» de Leandro Fernández de Moratín es la motivación inmediata de la «Respuesta de Jovellanos»'. Señala José Miguel Caso González que ambas epístolas se concibieron y fueron redactadas entre noviembre de 1796 y abril de $1797^{2}$. Moratín literaturiza en su eṕstola una serie de objetos poéticos próximos a las actitudes ilustradas mediante viejos tópicos literarios y ciertas fórmulas expresivas codificadas más o menos innovadoras, que serán recogidos, reelaborados y ampliados por Jovellanos.

"Epistola a don Gaspar de Jovellanos" de Leandro Fernández de Moratín

La obra, cntendida como comunicación con el amigo ausente según la radicional estructura epistolar, se abre con uno de los elementos clásicos del género: la dedicatoria, que desarrolla el motivo de la pura amistad. Este tópico, uno

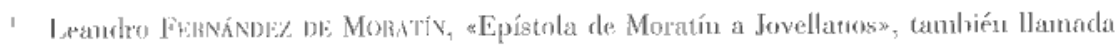
atpístola de Inarco Colenio a Jovino», Obras de Leandro Fernéndez de Moratin, tomo IV, Madrid, Imprenta Aguado, Cánora rle S. M. Casa Real, 1831, págs. 140-143. Tambiéu resogido en G. M.

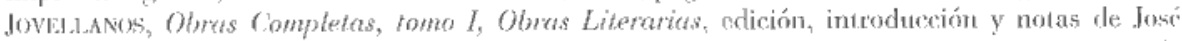
Miguel Citso González, Oviedo, Centro de: Estudios del Siglo XVIII - Ilustre Ayumanuicuto de Gijón, 1984, págs. 282-285. Gasprar Melchor de Jovlul LANos, «Respuesta de Jovellanos a Moratín*. Obras Completes, $10 m$ o I, págs. 285-200.

2 Para más detalles en tormo a los cliversos manuseritos y a su datación, ver las notas de

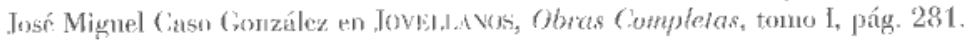


de los más frecuentados en estas composiciones, aparece representado sescún lá oposicióm de dos innégenes corificatlas en la tradición literaria: la medáfora del dulce nudo y la alusión a los interpuestos montes y al procelose mar.

La imagen paradójica del dulce mudo, una de las múltiples axpresiones deal

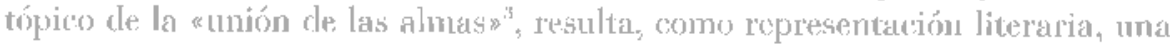
nada novedosa estucuctura opositiva de reminiscencias tradicionales, misticas y barrocas. Y sin embargo, csta metélora ha sufrido una metamorfosis. Más allá

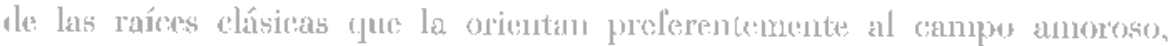
ampara anpuí el tema de la amistad. Este motivo se presema como manifestación romereta de los abstraces semtimientos jilustrados de frateruidad y lilantropía, y orupa nu lugér predominante en el mundo ideológico que la nueva mentealidad ha irlo configumanelo. Liste desplazamiento de una metáfora del campo amoroso al de la amistard se debe a la progresiva acogida de esas nuc:-

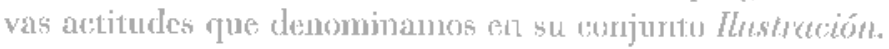

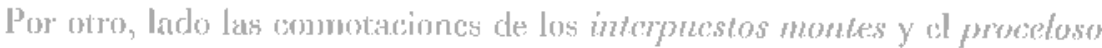

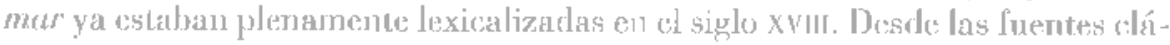

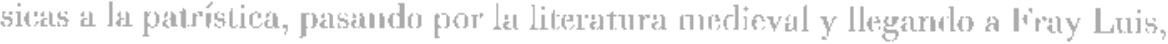
que es quien incjor sinteliza esta tradición, las inágenes del monte y el mar so

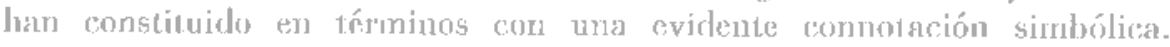
Lstructurados casi sicmpre como binomio, el mar suele representar ol caos, lo

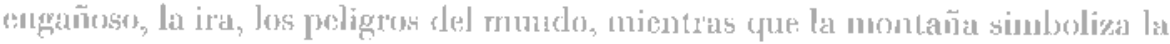
seguridad y la felicidarl del ascenso. Moratía mantieno las tradicionales connotaciones negarivas del mar", pero rechaza d semtido positivo an deaso de la

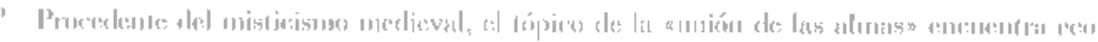

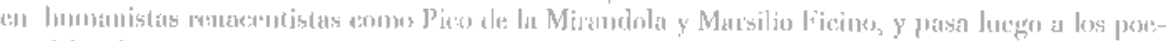

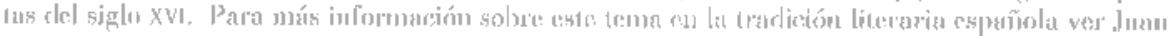

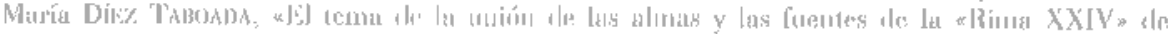

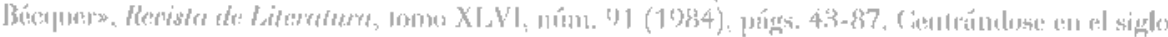

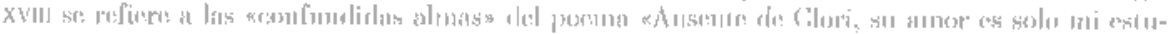

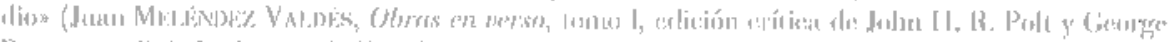

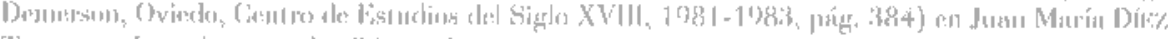

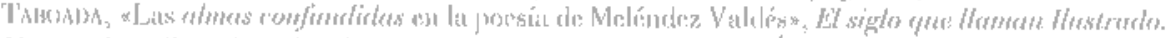

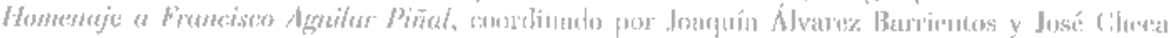

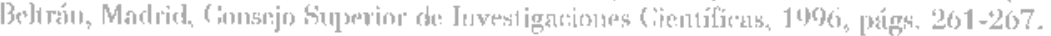

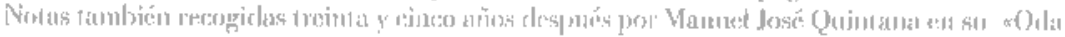

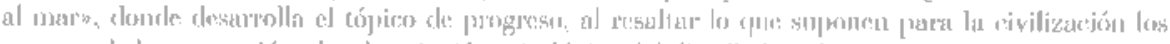

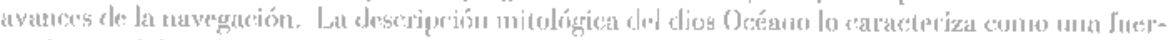

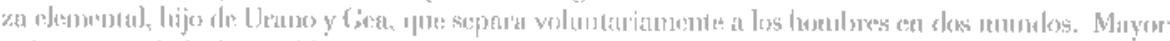

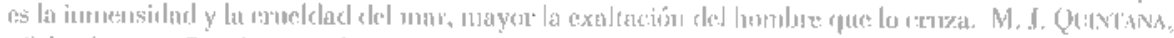

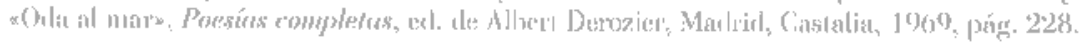


montaña, optando por una imagen con antecedentes tam reputados como las "ásperas montañas» te Garcilaso".

En la segunda estrofa plautea Moratín de modo circunstancial conceptos como la dulee paz o la deliciosa quietud que, opuestos al son de Marle según la estrtetura habitual en las dedicatorias, se verían irremediablemento abocados a nua interpretación de tintes pastoriles, si no fuera por la aparición del sintagma público bien, ya lexicalizarlo en la literatura jhostrada, que quiebra una tradición renacentista en la que el destinatario descausa de la guerra ocupado en actividades cinegéticas y amorosas, para situarnos súbitamente en las coordenarlas ideológicas contemporáneas de la obra.

A continuación, el motivo del viaje, elememto fundamental del programa cheativo ilusirado como instrumento de formatión basado en la experiencia que permite la comparación de culturas diversas, propicia el discurso sobre «cuanto a mi vista presentó el orhe» (v. 20). Lua presencia de este motivo cono organizador del texto lejos de ser excepeional en la literatura ilustrada, cristalizaría en los libros de viajes".

Esta descripeción dará lugar a la reflexión moral, elenento fundamental en las epístolas, junto a la insirucción y la sátira, desde que I loracio codificara el modelo clásico y Fernández de Andrada concretara las formas de la cpístola setecentista en la Epistolo morel a Futio.

la descripeión se desaroulla de acuerdo con los tópicos del Ubi sunté y de las ruinas - «destrozos del mayor imperios (v. 47) - Bajo estas fórmulats enuncia la sucesión de méritos y deméritos del Imperio romano, cuyo

abi de: mi baja lim

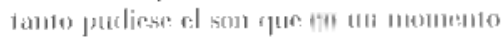

aplatisese la irat

alel amimose viento

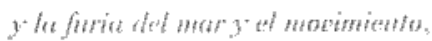

y en ásperts monthints

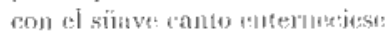

lins lievas atimañas $[\ldots]$.

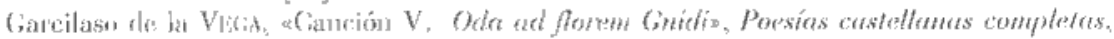

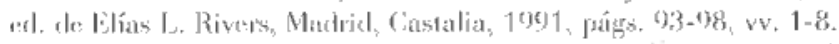

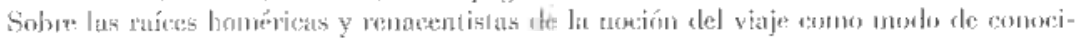

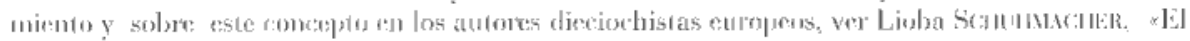

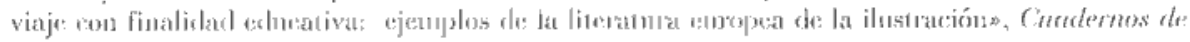

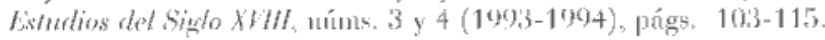


poder se plasma en esa imagen de los reyes bárbaros atados a los carros romanos en las procesiones de triunfo, que fuera formulada por Garcilaso en la "Ode ad florem Gnidi»?

El tópico de las ruinas se inserta en la tradición literaria ajeno a las connotaciones que serán codificadas por el romanticismo, a medida que se imponga la subjetividad conmovida del autor, fascinada e identificada con el paisaje". Lejos de tales innovaciones, el tópico se desarrolla segúm el lema Quanta Roma fuit, ipsa ruint docet, que desarrollaran Vitalis, Garcilaso, Cetina, IJerrera, Caro, Lope y Quevedo". Así, tuda la carga antimítica que conlleva la descripción de lo que Iejos de ser śmbolo del pasado glorioso es un signo de la miseria del presente, da lugar a la reflexión moral bajo la forma del tópico vanitas mundi. El predominio de lexemas de carácter negativo "Cayó", "desmoronados edificios», einformes masas» (vv, 48-62) refuerza el carácter desenganado del poema.

La correlación entre lo general y lo particular cu este poema es clara: bienes matcriales y fama de Roma han pasado, así los del hornbre, más adelante representartos por el «esomo intacto» del avaro y el «nombre inmortal» que promete la *adulación traidoras ( $\mathrm{v}$, 80-82).

z «nu pirnsess tpue candado

seria de mí, hemose flor de Cinick,

el liero: Marle: nirato,

[...] ni nipuellos rapitumes

ere hos sublimes modes colocatos,

pur rouien los alemanes,

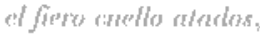

y los Cranceses vatu dumesicatos

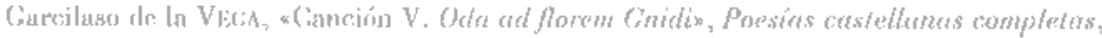
vv. $10-20$,

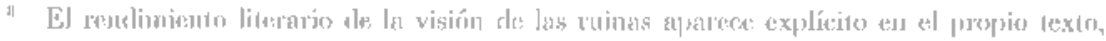

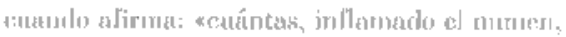

imáscusus sulblimes hallarias

an las elestrozos deel tunyos imperial o (vv. 45-47).

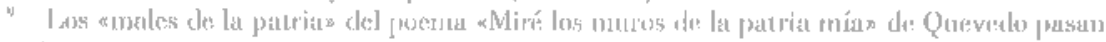

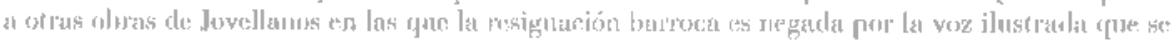
reluels:

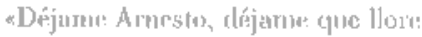

los fiems males de mi palriar

dija guse sus stuna y jerclición lamente.

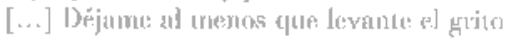

contra el alesarden:

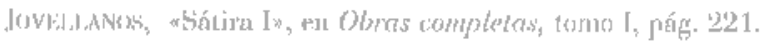


Moratín recurre a la imagen, lexicalizada ya, de la «débil flor», elemento fundamental de tópicos como el tempus fugit o el carpe diem "'. Renuncia a éste último por su carácter mundano, a menudo amoroso, y desarrolla los contenidos desengañados desde el primero para conchuir que todo, hasta el mayor imperio, pasa y es vano.

La caracterización negativa del hombre contemporáneo como colectividad una masa «vengativa, airada, envidiosa» (v. 85) que camina hacia su perdición "¿Por qué a la tumba presurosa corre?» (v. 84) remite a esa tradición oscurantista que interpreta la historia del hombre como un proceso de degeneración. "Todo es ruinas» (v. 87) concluye el yo poético y no le queda más que aludir al "mumen que anima el universo» (v. 92), el único que permanece eternamente.

Así pues, Leandro Fernández de Moratín permanece fiel a la tradición epistolar en la orientación fillusófica y moral propia del género, en cl que se frecuentaban temas como las veleidades de la lortuna, la brevedad de la vida o la disposición para el bien morir. T'ambién se mantiene en Jos cauces transitados en cuanto a los tópicos literarios según los cuales presenta estos contenidos, tópicos como el l/bi sunt? cuyo elemento fundamental es la enumeración de las grandezas del amor o del imperio, frecuentemente descritas como ruinas cuya visión da lugar a rellexión moral de sobre la vanidad del mundo, o tópicos como el tempus fugil, del que rechaza, eso sí, la vertiente renacentista del carpe diem. Para la formulación de tales tópicos remite a los ecos de autores clásicos" ${ }^{\prime \prime}$ e incluso se adapta a los modelos

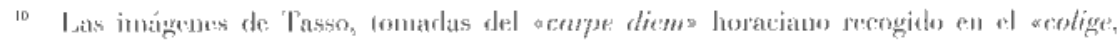

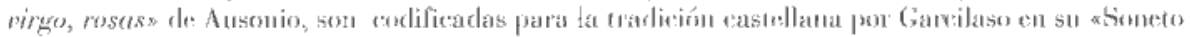

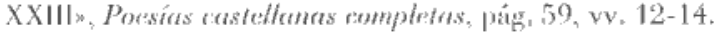

* Cogerl te: vacsira alogre primavera

el dules fruto, antes que el tiempo airado

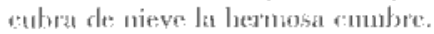

Marehitará la rosa en riempo helarlis.

corlo lo mutatió la colat ligera

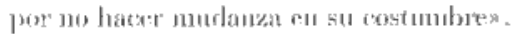

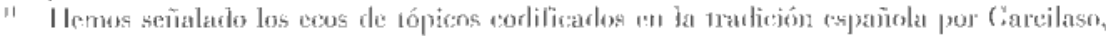

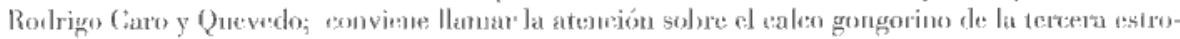

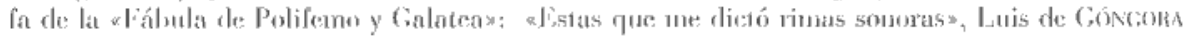

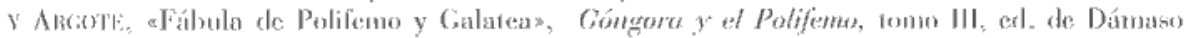
Alomso, Madrid, Ciredos, 1957.

«Estos que formon de primm tesmuklos,

no castigarlos de: 11 doma lima.

fúciles versess da verulad de anumciens (vv. 15-17). 
en la forma estrófica, ya que sigue el nodelo de la epístola familiar en versos sueltos, al que se oponía la epístola culta oreanizada en tercetos.

\section{"Respuesta de. Jovellanos a Moratin»}

De torlos los tópicos literarios, los motivos epistolares y los conceptos planteados por Moratím, mos típicamente ilustrudos, otros bastante más barrocos, Jovellatnos recoge ilgunos, remoze ortos y desarrolla bastantes más en sul "Respuesta", en la que a lo largo de 143 versos, transgredirá el código epistolar, al introducir, según veremos, una novedosa argumentación filosófica que acabará dando paso a la formulación mtópica.

Lar «Respursa» insiste con Moratín en la conveniencia del viaje para la formación del individuo y recoge la imagen del viajero que vence apeligrosos mares / y ásperos montes" (vv. 18-19) y así observa leyes y costumbres de otros pueblos, para dar pie al su discurso.

"Ĺlil ciencia artquirí, que nunca enseña

docka lección en retirado estancià,

que allí no ves la diferencia suma

que el clima, cl culto, la opinión, las artes,

las leyes catusan. Hallarasla sólu

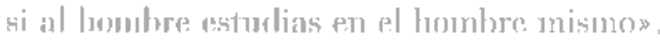

$$
\text { (Moratín, vv. 29-34). }
$$

« Oh, qué mudanza! ¡OH, qué Jecrión1! Bien alices:

la experiencia do instruye. Sí del hombre

ho: aquí ol más digno y provechoso costudios.

$$
\text { (Jovellanos, vv. 2(3-36). }
$$

Pero desde el primeipio Jovellanos se sitúa en un plano contemporáneo al qua había renunciado Moratín y es testieso, no sólo de las ruinas del pasado. sino tambión de acontermientos cono la Revolución Francesa. Ia descrípción de un entorno en constante cambio da paso a la interjeretatción de tal visión del mundo a traves del agente de liss cambios: el hombre, lo que permite a Jovellanos ensayar una valoración del papel rie éste en el mundo.

Analizaremos ahora rómo noverdosos planteannientes filesóficos-dualidarl humana, perfectibilidarl individual y progreso social-y míticos -Erlad de Oro-, flue se ven comvertidos on ulopia meteed a la proyección lutura que se les imprime, dan cuerpo a la epístola. Jovellanos fornula la conexión entre la idea 
ilustrada de perlectibilidad y el mito de la Edad de ()ro, dos conceptos hásicos en la historia de la cultura oecidental para la comprensión de lás consideraciones sobre la condición humana, en los siguientes términos: si el hombre es perPectible será posible que vuelvan los días de la lidad de Oro.

Evidententente, los conceptos que acabamos de exponer sólo nos tesuliarán comprensibles en el marco de las reflexiones sobre el individuo y su relación com la sociedad que caracterizan el sistena ideológico ilustrado. Pero no se trata aquí de coneretar qué contenidos filosólicos se desarcollan en la epíslola y en qué contexto ideológico se producen, sino de ver en qué manera el discurso filosólico y el mítico organizan la estructura del poema.

Las ideas de dualidad, perfectibilidad y progreso como argmmentación filosófica y estructura de la epsistola

Dualidud. En 1755, Jean Jacrues Rousseau presenta a la convocatoria de la Academia de Dijon su Discurso sobre el origen de la desigualdad entre los hombres, en el que sostiene que el desarrotlo social ha sido una cefuivocación hunama, enlirentándose al optiunistu progresista de los enciclopedistas. Según Rousseau, más se ha apartado el hombre de su estado primitivo y más desigualdad se ha producido. En sus reflexioues opone los conceptos «civilización» y «sociedad» a "naturaleza», lo que le lleva a distinguir "hombre social»y "hombre naturat", y concluye que de la vida social proceden iodos los males: la propiedad privada, las desigualdarles, la guerra y la esclavioul. Paralelamente diferencia «ley natural» y «bey instinucional». Fin este caso el discurso filosófico remitióa al literario para sus razonanientos y Rousseau recurrirá al mito de Antígona (representante de la ley de los dioses o ley natural) y Creonte (representante de la ley de la ciudad o ley social) para juzgar imeduetible este conflioto entre las «virtudes luumanitarias» y las "virtudes sociales». Fue el propro Rousseau quien rastadó csta escisión al interior del hombre, considerándolo una realidad dual, hombre y ciudartano al riempo y en conflicto, de alí su sentencia: «Volved al hombre uno y será feliz».

Estu idea de dualidarl estruetura la «Epístola de Jovellanos a Moratín», en la que se marca la escisión entre las acciones del hombre. El hombre de Jovellanos una veces mejora los dones de la naturaleza, mediante la industria. y entonces se comvierte en luerze de progreso, por to que sus acciones se valoran positivanente: "esfuerzos de: la industria humana», "varia, fecunda, gloriosa y llena / de: armor, de unión, de movimiento y vidas (vv. 30-32); otras veces se aparta de las leyes de la naturaleza y cutonces se suceden los semas 
negativos: "loca ambición», "rabia insana», "guerra, furor, desolación y muerte» (vv. 34-35). Más adelante la oposición signe rindiendo y la dicotonización se ve rraducida en la asociación distributiva del hombre al cielo y al averno - Tal es el hombre» (v. 36)-. segúm las acciones descritas y con todas las asociaciones y oposiciones que de esta complementariedad se siguen: "virtud», "piedad», afiel, humano, oficioso», «amor y fraternal concordia», sse solaza y ríe", "ama y socorre, llora y se conduelew (vy. 37-42); frente a esta cnumeración encontranos sintagmas como la "enemiga antorcha", "Irenético bramandos, «quema, mata, asuela» (vv. 44-46).

Tal dualidad es descrita en la línea de Rousscuu como una shado crnel» (v. 49) y un «adverso influjo» (v, 51). Aunque Jovellamos sostiene la idea de que: algún instinto lleva al hombre a la guertea, lo gue en cierto modo le exculpa do: sus acciones, mantiene la dicotomía amar / orliar como expresión de la realidad.

«Ni amarle puedes, ni odiaule: puedes

tan solo ver con lástima su hado,

hudo cruel, gue a encmistud y rraude

y susto y guerra warua le conduces.

(Jovellonos, vv, 47-50).

Peffectibilided. Pero Jovellanos ante la progunta \&Quét ¿El hombre

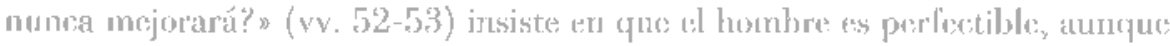
Rousseau había sido cavegórico al negar la reconciliación entre las dos naviralezas de: la condición humana, representades por Antigona y Circonte.

lin 1750, la Arademia de Dijon organiza t1ma convorétoria sobre la concsión de qué condiciones favorecen la perfectibilidål. Én ella es prenuiarla la vooría de la regresión histórica de Proussexu, que defiende la espontancidad nadural del hombre: frente a la línea lilosolica yue aboga por moldear sut cááder mediante leyes e instituriones sociales, al situar en la naturaleza humara la sede de las perversiones. Iin un contexto de desconfianza en el individuo y partiendo de un conponente predoninance de soriahiliclad en su teoría de la perfectibilidad, Hoblues, abbe de Saint Picre o Kant conceden a las instituciones un poeler inconmen-

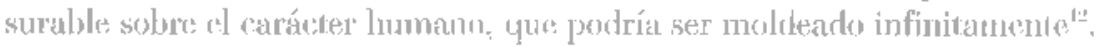

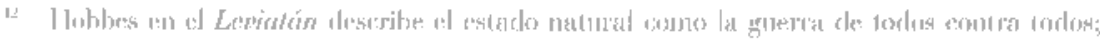

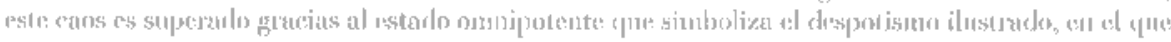

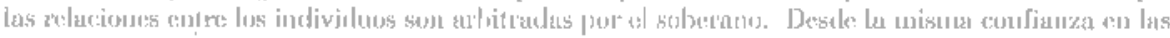

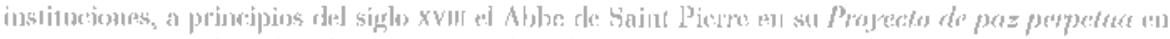

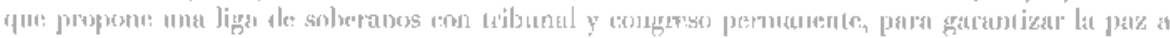

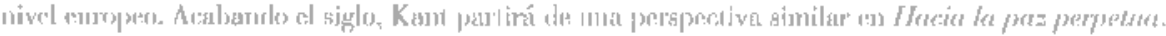


Jovellanos tiene que solucionar literariamente la escisión planteada al comienzo de la epístola. Optará por la vía rousseauniana en cuanto que supone en el hombre ma unidad y armonía primitivas que se vieron truncadas, pero renunciará a ella al admitir la posibilidad de teconciliación entre ambas naturalezas. Jovellanos estructura los versos que siguen en función de las dos vertientes fundamentales de la teoría de la perfectibilidad: la perfectibilidad de la razón y la perfectibilidad del corazón.

La perfestibilidad humana suele estar asociada a la idea de instrucción, ya que según la mentalidad ilustrada uno de los pilares del progreso es la educación individual y social. De ahí que el motivo del viaje, clemento importante en la formación del individuo, abstraído en la respuesta de Jovellanos más allá del motivo particular de Moratín, aprarezca en los versos que preeden a los que desarrollan la idea de perfectibilidad. Jovellanos en su Memoria sobre la educación pública alirmaba:

* ¿No es la instruceión la due desenvuelve las facultades intelectuales y la que aumenta las fuerzas lísicas del hombre? Sin ella su razón es una antorcha apagada; (...) Así es como la instrucción mejora al ser humane, el único que puede ser perleccionado por ella, el cumico dotado de perfectibilidad $x^{1:}$.

Aceptado que el hombre es susceptible dr mejora, que su razón es perfec:tible, Jovellanos vincula el estado de perfección a la virtud y lo considera procedente del cielo (vv. 30-42). En las consideraciones rousseamianas, este estado aparece teñido de un carácter paradójico: se maniliesta en un universo que: ignora la distancia entre el bien y el mal, porque el hombre natural no es bueno intencionadamente y este estado fue sienpre ajeno a su razón. $Y$ sin embargo, Jovellanos, lejos de identificar el estado natural con el estado de perfección, alude al primero como el de la «salvaje, estúpida ignorancia» (v. 5.5), renunciando, una vez más, al discurso rousseamiano.

Pero Jovellanos se resiste a la dicotomía razón / sentimiento, más tópica que real en el movimiento ilustrado, y opta por la unión de ambas potencias, también equivalentes en su Memoria sobre la educación pública y asociadas en una codificación literaria a la que recure con frecuencia:

«Ea, pues, claro que la razón humana se perfecciona por medio de la ins. traceión. Pero zpor ventura se perfeccionará también por este medio el corazón de] hombre? ¿se perfeccionarán sus sentimientos morales? [...].

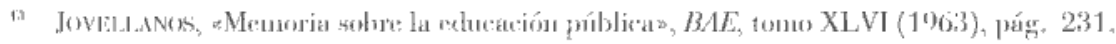


Sin dudá. La distinción que se laqce de la razón y el corazón del hombre es una de las metáforas que pueden haber dado origen a muchos crrores: los sentimientos como las ideas, resider en el glma. jNo es suya la laculadd de sentir como, la de pensar? ... Nu se pueden separar los semtimientes de las ideas ni suponer un sentiniemo morel sin suponer la conexistencia de una ideas ${ }^{1+}$.

*[...] Si perfectibls:

nació; si pudo a la mayor cultura

de la salvaja estúpida ignorancia

salir $[\ldots]$

" [...] por lin si pudo

perteccionarse su razón, jtan sólo

sevád a su ticrno corzzón uegada

la pestutrión? 15.

«Sabiduría y virtud som dos hermanas

Arscondidas del cielo para la gloria

y perfección del hombre. Le alejando

del vicio y del engaño, ellas le acercan

a) Iavinidads".

Lin esta línea de pensamiento que relaciona la l'azón y al corráun en el proceso de perfectibilidad, podemos recordar la propuesta de la Acádenia de Dijon de 1750, que planteaba el dilema de si el renacer de las riencias y de las artes había contribuido o no a mejorar la moral. Ll ensayo premiado de Rotesscalu cra bastante menos alentador que estas alimaciones de dovellanos.

Una peculiaridad del planteamitnto de Jovellanos es que no se limina al plano humano y considera tal perleccionumiento como un acercamiento del

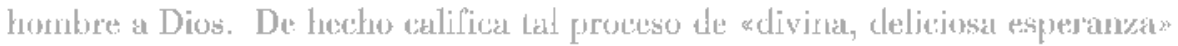
(vv. 68-69), adelantando ya dos maties lundamentales de lá argnmentación:

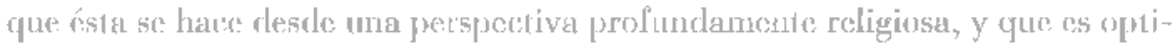
mista respecto al fucuro, aunque literariamonte la escisión humana no se superará hastu st final del permal.

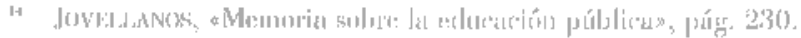

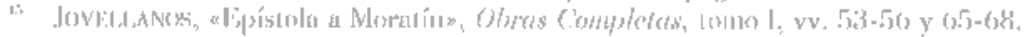

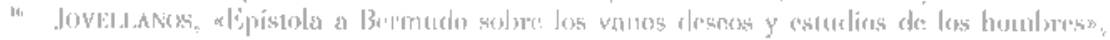
Obras complelas, lesum I, prig. 314. 
Progreso. La idea del avance cognoscitivo, de perfectibilidad, ya arraigada a comienzos de siglo, va extendiéndose del terreno individual al plano social, y conduce a la idea del progreso general de la humanidad. Así se abre lá posibilidad de una 1ransformación radical del edificio social. Jovellanos estructura la segunda parte de la epístola según la escisión que había apuntado en cl hombre.

Por una lado defiende, según la vía rousseauniama, que de la vida social proceden todos los males: la propiedar privada, las desigualdades, la guerra y la esclavilud. Pero desde la perspectiva cristiana en la que se sitúa Jovellanos, lo que para Rousseau era ley de la naturaleza, para Jovellanos es ley de Dios, lo que hombre natural, hombre del cielo, lo que hombre social, hombre del averno, lo que le lleva a concluir:

« Oh sociedad! ¡Oh leyes! ¡Oh crueles

nombres, que dicha y protección al mundo

engañado ofrecóis, y guerra sólo

le dais, y susto, y opresión y llanto!n.

(Jovellanos, vy. 82-85).

Por otro lado, se confrenta a la idea de que la historia de la civilización es un proceso degenerativo, según la concebía Rousscau y recogga Moratín, apoyándose en el desarrollo que entones venían teniendo la astronomía y la navegación. El tópico filosólico de los descubrinientos científicos, los avances técnicos y los hallazgos artísticos es utilizado por Jovellanos como argumentación literaria del progreso de la humanidad (vv. 54-65). Lstos avances fueron una de las principales imágenes del topico de progreso, desartollato en el corpus de: poesía científico-técuica. El rema fue explícitamente propuesto en 1800 por Quintana en su justificación de la oda "A la invención de la imprenta»:

«Lac ocasión di haberse compuesto este ensayo poético en clogio de la invención de la inprenta, fue haber lédo las siguientes límeas en el artículo "Arte» de la Enciclopedica. "I lagamos en fin a los artistas la justicia que se les debe. Bastante se han cantado a si mismas las artes liberales; ellas podrían ya emplear su voz en celebrar las artes mecánicas, y en sacarlas del olvido donde las preocupaciones las han tenirlo tanto tiempo" Con efecto además de la invención de la imprenta, que offece otros mil aspectos por donde poder considerarse, la de la pólvora, la de la aguja náutica, y algunas otras, son objetos que pueden enriquecer la poesía de una infinidad de bellezas originales» ${ }^{17}$.

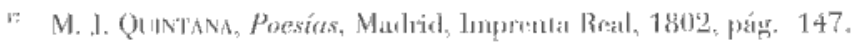


La lielicidad a la que lleva el foreciniento de las ciencias genera la alabanza *A la invención de la imprenta"; el progreso rque suponen para la civili-

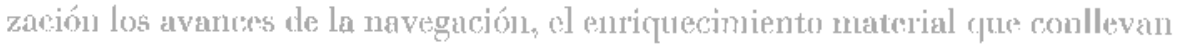
para Europa y la unidad que proporcionan al mundo, dan cuerpo a la soda al mar"; el beneficio para la polblación americhne de un medio de prevención para una enfermedad que diezmaba las pob]aciones articula las odas «A la expedición española para propagar la vacuna en América bajo la direceión de don Francisco de Bahmis» y "A la vaemia» de Andrés Bello ${ }^{13}$.

La nueva riencia experimental había condicionado el pensamionuto del siglo XvIII lasta el punto re ser considerada pilar fundamental de la utopía muderna. Di alí que la presía cientílico-téenica celebre los descubrimientos y avaneses de la física, la quínica, la botúnica... fodo lo que supone mu progreso para la loumanidad. La argumentación no es redicalmente novedosá. I_os avances de la cirencia ya habín sido considerados como prucba del progreso de la liunanidad por humanistas renacentistas como Tomás Campanella, fuien

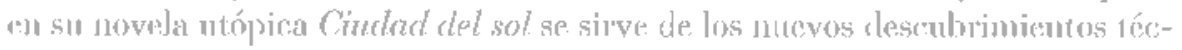

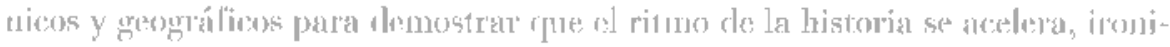
zando sobre lat negación que hicierun los filósofos y teólogos medievales de que existieran liss antiparlats, negación ya refutarla por los viajes de Cristóbal Colón. Que estos presupuesios filosólicos sean o no noyedosos no nos importa ranto como que temas que antes no cran percibidos como materia poética, seneren ahora nuevos mundos litcrarios vedaros a la literalura iradicional.

It mito de la bilad de ono como expresión de la wopia de progreso

Jin la «Respuesta de fovellanos a Moratín, la argumentación filosólica sobre la escisión, la perfectibilidad y el progreso humauos, da paso a la expresión de la utopía política, formulada literariamente según ol mito arédico de la Fidad de Oro, codificación por excelencia de un mundo on concordia.

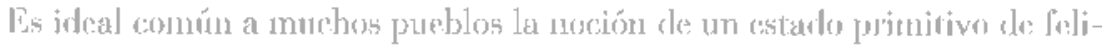

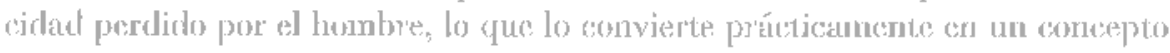

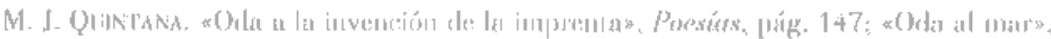

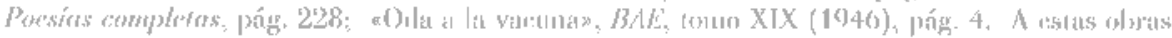

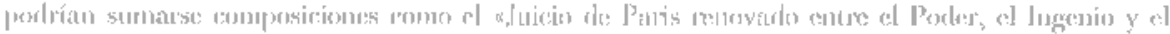

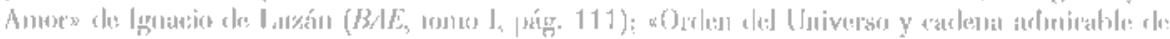

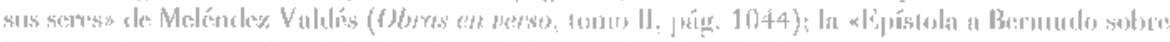

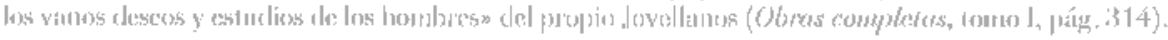


antropológico. La forma orcidental de este ideal está codilicada por primera vez en Los trabajos y los días de llesíodo, que alrededor del año 700 a. de C. describió el tiempo de Cromos como la Edad de Oro, en la que individuos inocentes, que no necesitan trabajar pues tienen las necesidades básicas cubiertas, viven una elena primavera. Omo elemento fundamental del mito arcádico era añadido por 'Teóndo haxia 300 a. de Ca: el amor cumplido. Virgilio en sus Bucólicas aporta hacia 41-30 a. de (i. otro aspecto que se constiunái en piedra de roque de las disertaciomes toropicas: en su mumdo idílico no existía la propiedad privada. Poco más labtaba ya para la conliguación de la rádición literaria, que la adapración cristiana del mito judio del paraíso ampliado lacia Al futuro con al redorno de Cristo oras el Apocalipsis.

Concelida como ma era pasada, atenclicudo a los componentes grecolati-

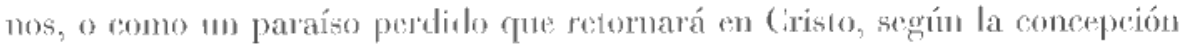
julco-cristiana, el mito permenceréa en la conciencia occiclental reapareciendo de 1 anto en 1 anto como la finmulaxión por excelencia de mo mundo en paz.

John Milion habóa rececado el mito teligioso de los origenes en su obra Praredise Lost (1067) on finalidad moral. Pero lejos de la argumentación filosófica, Milıon había recentido a la natración épica de la historia sagrada (los mismos cátomes resele los yue cuatro años después abordaría el tema de las tentaciones de Jesús en el desipsto en Paredise Regained). Sin duda, el humanismo cristiano de Milion hubo de atraer a Jovellanos, lo que le llevó a jubenar la traducejón del poerra, que también habia llanado la atención de (iadalso

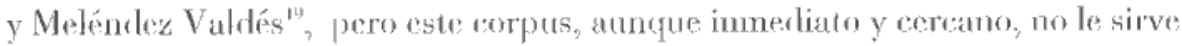
como modelo a Jovellanos, pue cestructura el poema directamente desele el mito clásico y el cliscurso filosólico conlemporáneo.

Portría parecer paradójico que elespués de haber intentado la explicación racional del progeseso en funcjón de los avances de la ciencia, Jovellanos renurtcic al discurso argumentativo para volver a la explicación mítica de la realidad. No hay lal. Por un larlo, este cruce de discursos, totalenente lícito en el campo literurio, tenía precedentes cocanos en canpo en los que era mucho más peligroso, como el econónico. El arbitrismo, que había sido capaz de emunciar válidanente las causas reales de la crisis castellana a principios del siglo XVII. seguía intentando resolverla en el siglo xy

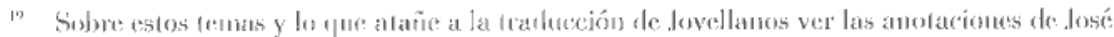

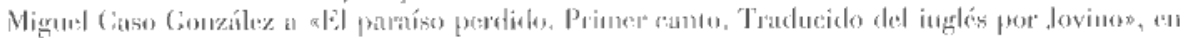
lovela INos, obres completes, fomo I, prigs. 122-126 
carácter mesiánico. Por otro lado, para construir su discurso en torno a lo que evoca como «la concordia de los siglos de oro, sus inocente's y serenos días" (vv. 93-94) y adecuarlo a la formulación ilustrada, Jovellanos remoza las codifieaciones míticas precedentes, al seleccionar, reelaborar y absundonar determinados elementos e incorporar otros nuevos.

¿O había en la formulación clásica del mundo mírico un «industrioso chino», un "colono», un "marinero», o ese tan ilustrado "nísero artesano»...? (vv, 111-130).

Jovellanos renuncia al motivo amoroso introducido por 'Teócrito, que no fue considerado por los ilustrados como objeto suficientemente nohle para lormar parte de su utopía, ni por lo tanto de la nieyoría de los poemas filosóficos. Renuncia tambión al elemento hesiódico y búblico del descanse constanle. En un contexto social en gute la combonía es casi exclusivamente dependiente de una precaria agricultura y un inestable comercio, la ideología ilustrada pretende estimular desde el propio golsiemo el culo al trabajo, al tiempo que promulga un nevo calendario laboral, declara a la mujes bábil para los trabujos falmiles y dicta keyes contra los pobres no trabajadores. Lejos de la concepsión del trabajo como un castigo, que subyace en la máxima "Canarás el pan con el sudor de tu frente», el tórmino "trabajo» tienc en cste contexto una valoración positiva y es considerado acimiento de la felicidad pública *ta $^{20}$ Por ello Jovellanos en su epístola presenta una versión muy ilustrada del nuito cle la Edad de ()ro, en rue «será el trabajo / pensión sagrada para todus» (vv. 132-1393)

Sin embargo, Jovellanos acoge el elemento mítio virgiliano de la ausenria de la propiedad, a la que considera aluente y sola causa de tanto mal (vy. 91-92). Al ocuparse del varúcter hereditario do los mayorazgos en su Informe sotre la Ley Agraria expresalua consideraciones semejantes:

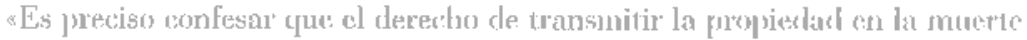
no está contenido ni en los designios ni en las leyes de la naturalezá. [... [ y

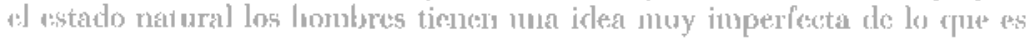

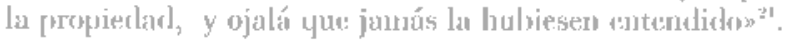

liśa revelabotación del nito de la Edad de Oro, que labbia circulado ampliamente en la literatura clásica esprañola, no sólo estalsa en la mente de

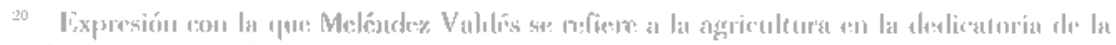

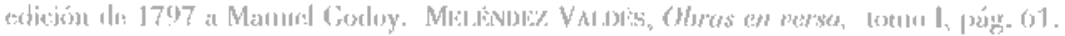

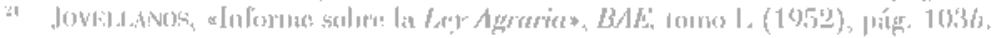


Jovellanos. En cl siglo XvIII era también recordado por el naciente socialismo utópico. Meslier en su Memoria acerca de los pensamientos y de los sentimientos condena la resignación propugnada por la religión y propone la igualdad de bienes, línea en la que se halla el socialismo populista de linguet y Deschamps; Morelly en el Naufragio de las islas flotantes o Basilade y en su Código de la naturaleza propugna una sociedad comunista eistaitica y el estabecimiento de $u$ sistema de cooperación y asistencia nacional; Mably pide el retorno a un primitivo comunismo agrario ${ }^{22}$.

El descubrimiento de la vida salvaje coetánea americana y las noticias sobre esas sociedardes presuntamente igualitarias son descritos desde el mito de esa commidad primitiva que vive en un régimen igualitario de propiedad común, en que reina la concordia y no existe la envidia. Todos estos factores habían venido generando una serie de elcmentos de ficción que se inserraban bajo formas míticas y literarias en discursos que en realidad aspiraban a ser históricos, como las crónicas americanas. Precisamente en éstas y en las Cartas colombinas encontramos el germen del tópico del «fuen salvaje» que cristalizaría en el mito dieciochista del "noble salvaje», un particular punto te vista sobre la perfectibilidad humana. Pero no todos confunden discurso histórico y discurso mítico. Feijoo niega la historicidad de la Edad de Oro, y con ella la lectura de la historia cono proceso de degeneración, considerándola precisamente discurso mítico, literario, y llegando a cuestionar el alcance de la versión cristiana del paraíso perdido:

"[..] se engañan mucho los que piensan que los siglos se fueron maleanfo así como se fueron sucediendo. La edad de oro no existió sino en la idea de los poetas; la felicidarl que fingen en ella, sólo la gozaron un hombre y wla mujer, Adán y Éva, y eso con ranta limiación de tiempo, 'que bien lejos ale llegar a un siglo, según muchos padres, no duró un día enterown.

Ahora bien el mito tiene limitado su campo de acción a la proyección hacia el pasado, por lo jue no presenta solución a los problemas planteados por la argumentación liblosófica de Jovellanos. Sin embargo, tanto d

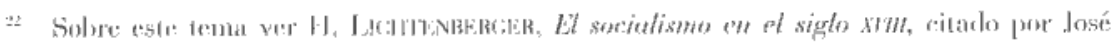

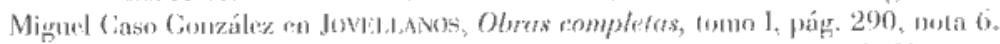

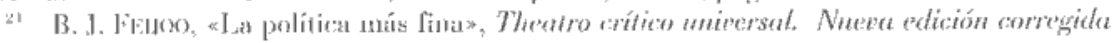

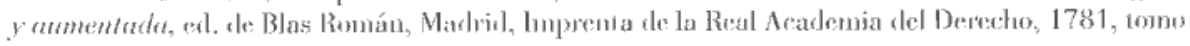
1. diseuran IV, vapítulo I. 
discurso mítico cono el utópico mantienen en común la negación de un presente que se juzga negativn: por lo que pueden ser relacionados. De ahí que Jovellanos retome el mito de la Edad de Oro y lo proyecte hacia al futuro, otorgándole carácter utópico, para proponer, no la vuelıa al pasado, que formulara Rousseau, simo el retorno de los orígenes, del ideal pasado en ol futuro, pero, y esto es radicalmente novedoso, conservando los avances históricos, cientílicos y culturales que habían hecho progresar a la humannidad.

No era la primera vez que Jovellanos recurría a esta imagen literaria. Va hacia 1780 había formulado el mito de la Lidad de Oro como contrapmuto de la anoralidad que reina en la corte en su "Sátira I. A Amesto", pero no encontramos en tal composición proyección funtura alguna sino la mera crítica al riempo presente:

*l lubo un liempo en que surdaba la modestio

doramelo los delitos; lintro un tiempo

al que el recato timido culvía

la fealdad del vicio; pero huyúse

ol pudor a vivir en las cabañes.

Con él huyeron los dichosos días,

que ya no volverán; huyó aquel siglos".

Sin embargo, on la eLpístola de Jovellanos a Moratín las interrogadciones retóricas dan pie a la proyección liacia el futurn como forma de expresión de la convicción del pocta de que aquel tiempo volverát

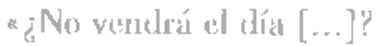

¿ No vendrá el día [...]?

Peru vendrá aquel día, vendrá, Inarco

a iluminar la tierrac y los cuitados

morlales consolar $[\ldots]$.

[...] la comeorrlia de los siglos de orre,

sus inocentes y serenos días;

empero al fin solbre el lloroso mundo

a lucir volverán».

(Jovellanos, vv. 70, 77, 86-88 y 93-96).

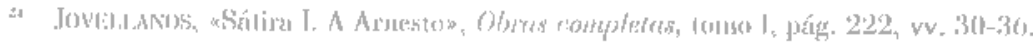


I a conlianza en el futuro es un atributo de la filosofía denominada progresista. Turgot en su Discurso sobre el progreso del espiritu hamano (1750), Lessing en La educación del género hmmano (1780) y Condorcet en su Bosquejo de un cuadro histórico del progreso humano (1793) y Kaut en todas sus disquisiciones históricas insisten en la noción de una evolución de la humanidad lacia un estadio superior. Aunque tal creencia entra en crisis en hombres como Voltaire, que van tornándose paulatinamente escépticos, podemos decir que se mantiene como hase de los proyectos progresistas ${ }^{23}$.

En este contexto, la utopía moderna se comfigura como un proceso civilizador, cuya últina instancia, y máxima utópica por excelencia del proyecto ilustrado, es la afelicidad pública», a la que llega el país mediante la conjumción de lactores diversos: la educación, el trabajo, la virtud, la relación fraternal, la liberiad cuando oprimidos... Concluye losé Antonio Maravall:

«Civilizar viene a expresar una acción temporalmente desplegada, un proceso al que han de tender quienes gobieman a los hombres, a lin de dotar a los mismos de los recursos morales, educativos, cientílicos, téenicos, conómicos... que confieren a un pueblo una posición avanzada en su desarrollo histórico» ${ }^{2}$.

Bien scñaló José Miguel Caso el carácter wópico de estos ideales:

«Pero esta meta última es una utopía política, porque cn las Reflexiones sobre educación pública dejó bien claro que al progreso lo llama indefinido en cuanto no se conocen sus límites, no en cuanto que no los haya ${ }^{27}$.

La civilización no es la realirlad recordada, ni siquiera la conseguida, sino d icleal al que se liende. Esta idea de proceso en desarrollo, no concluido, quizá sca el más claro exponente de ese conjunto de actitudes, a veces sólo difusamente delimitadas, que denominamos ilustración. De alı́ que la esperanza sea un sentinicuto básico en la conformación de lo que podemos consi-

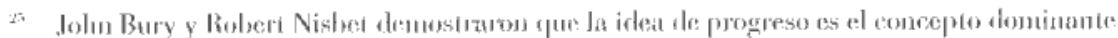

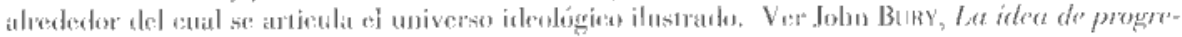

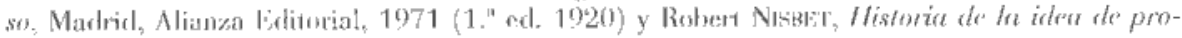
greso, Barcelona, fedisa, 1981 (1." ed. 1980).

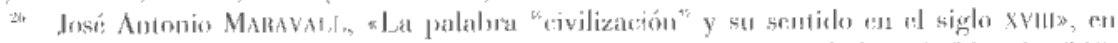

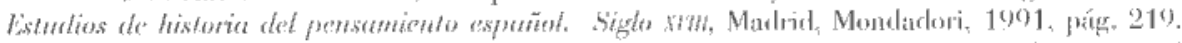

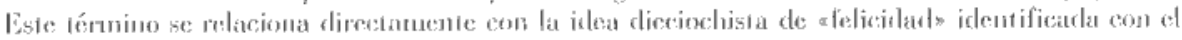

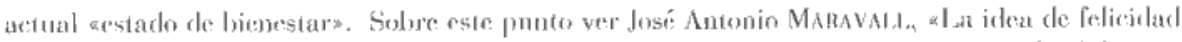

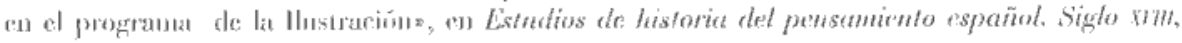
lígs. $162-189$.

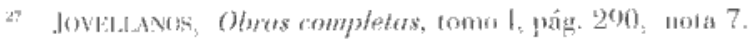


derar «la utopía moderna»"s y la alusión al nuevo hombre hermanado con la sociedad, a la "nueva generación" (v. 108) que desde entonces vivirá en la tierra en réginen de trueque.

En los últinos versos de la epístola encontramos sólo lexemas que denotan indivisibilidad, superada la escisión, para describir una humanidad que canta «al solo Autor de todo» (v, 143): «un solo pueblo», «una sola y gran familia», «un solo común inioma», «indivisos términos del mundo», "ura

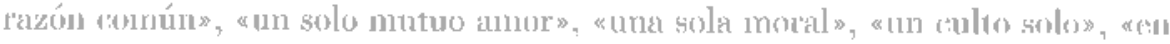
santa unión", "el nudo estrecharáñ", "nin solo himno», adel Austro a los T'rioness -de sur a rorte- (vv. 114-140).

También la epístola de Moratín acababa con la misma alusión a Dios, pero al desarrollar el tópico literario del tempus figit, aquí la alısión se ceñía al sema de la eternidad divina frente a la fugacidact tel mumbo, lo que sitúa al poema en una perspectiva mucho más barroca y desengañada respecto a las posibilidarles del individuo.

Jovellanos en cambio renuncia al tópico e intenta formular una nueva vía, mediante la idea de la mudad que Dios proporcionid al hombre como individuo, al honbre como sociedad y a ésta con cl Linverso, desde una perspectiva antropocéntrica ilustrada que mide lits relationet en función ale su climensión humanda.

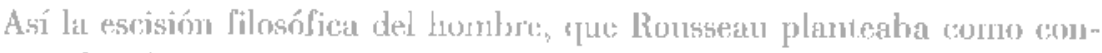
flicto irredurtible, se ve superadia por la unilad divina, y las virtudes humanilarias y las sociales se ven utópicanente conciliadas.

El desengaño lleva a Moratín hacia el discurso religioso, fil optimismo ilustrado de Jovellanos, Hubitativo ante las posibilidades de la naturaleza individual humana, pero confiado en la civilizatión de la humanidad como coleclividad, le dirige hacia e] discursu ulópico.

Dirigida a una pescona específica y mareo re contenidos filosioficos. que aún habrán de esperar para ver configurado en la forma del ensayo su propios discurso, esta ppístola ilustada no innova formalmente la estrue:-

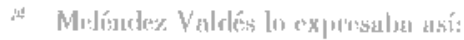

\&[...] P’ues que nu alcanzit,

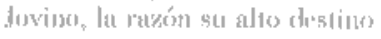

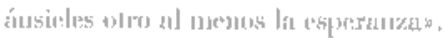

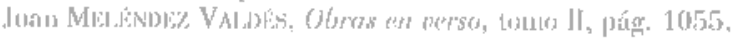


tura epistolar codificada por Horacio. En cambio, genera nuevos tópicos literarios, como la perfectibilidad, la civilización, la unidad fraterna de los hombres..., que modernizan contenidos filosóficos tradicionales de la poesía como el ubi sunt?, el tempus fugit o el carpe diem, y remoza antiguos mitos, como el de la Edad de Oro, porque se sirve tanto de discursos filosóficos como míticos para expresar literariamente la utopía moderna. 